\title{
DETECCIÓN MÚLTIPLE DE SNPS RELACIONADOS CON CRECIMIENTO Y CALIDAD DE CARNE EN PORCINO
}

\author{
MULTIPLEX DETECTION OF SNPS ASSOCIATED WITH GROWTH \\ AND MEAT QUALITY IN PIGS
}

\author{
Padilla, J.A. ${ }^{1 \mathrm{~A}}$, Portilla, F.J. ${ }^{1 \mathrm{~B}}$, Salazar, J. ${ }^{1 \mathrm{C}}$, Parejo, J.C. ${ }^{1 \mathrm{D}}$, Martínez-Trancón, M. ${ }^{1 \mathrm{E}}$, \\ Rabasco, A. ${ }^{1 F}$, Sansinforiano, M.E. ${ }^{1 G}$, Corral, J.M. ${ }^{2 A}$, Izquierdo, M. ${ }^{2 B}$ \\ y Hernández-García, F.I. ${ }^{2 C}$
}

\begin{abstract}
1Departamento de Producción Animal y Ciencia de los Alimentos. Facultad de Veterinaria. Universidad de Extremadura. Campus Universitario s/n. 10071 Cáceres. España. Ajpadilla@unex.es; Bjaviport@gmail.com; cjsalazar@unex.es; Djucapar@unex.es; Emartinez@unex.es; Farabasco@unex.es; ${ }^{\circ}$ sansina@unex.es; ${ }^{2}$ Centro de Investigación La Orden-Valdesequera. Junta de Extremadura. Apdo. 22. 06080 Badajoz. España. Ajuanmanuel.corral@juntaextremadura.net; ${ }^{B}$ mercedes.izquierdo@juntaextremadura.net; c francisco.hernandez@juntaextremadura.net
\end{abstract}

\section{PALABRAS CLAVE ADICIONALES}

Minisecuenciación (primer extension). Loci HFABP. Loci MC4R. Loci LEPR.

\section{RESUMEN}

Se describe un método basado en análisis por primer extension para genotipar simultáneamente 7 SNPs relacionados con el crecimiento y la calidad de la carne en porcino. Las muestras de ADN genómico fueron obtenidas de 193 animales pertenecientes a varias razas (54 Ibérico, 63 Duroc, 47 Large White-Landrace $x$ Large White) y a jabalí (29). A partir de las secuencias de los genes $\mathrm{H}$ FABP, MC4R y LEPR, se diseñaron 4 parejas de cebadores con el fin de amplificar las regiones del genoma porcino que contienen esos 7 SNPs. La reacción de minisecuenciación primer extension (ABI PRISM SNaPshot Multiplex ${ }^{\mathrm{TM}}$ kit. Applied Biosystem) se realizó con cebadores diseñados en las regiones flanqueantes de cada uno de los SNPs de interés. Los genotipos fueron identificados por mini-secuenciación con ABIPrism 3130 y GeneMapper 3.7 (Applied Biosystems) pudiéndose así discriminar, en una sola reacción, los diferentes alelos de los 7 SNPs de cada animal. Gracias a esta técnica han sido detectados los polimorfismos T221C y C233T del gen LEPR (Genbank AF092422), que no eran reconocibles por enzimas de restricción. Este método permite identificar los animales con genotipo más deseables para la selección.

Recibido: 6-2-08. Aceptado: 22-10-08.

\section{AdDitionAL KEYWORDS}

Minisequencing (primer extension). Loci H-FABP. Loci MC4R. Loci LEPR.

\section{SUMMARY}

This work describes a method based on primer extension analyses to genotype simultaneously seven SNPs associated with growth and meat quality in pigs. Genomic DNA samples were obtained from 193 animals belonging to several porcine breeds (54 Iberian, 63 Duroc and 47 Large White-Landrace $x$ Large White) and 29 wild board. Four pairs of primers have been designed from the sequences of the genes $\mathrm{H}$ FABP, MC4R and LEPR and were used for the multiplex amplification of regions in the pig genome containing seven SNPs. Primer extension reaction (ABI PRISM SNaPshot Multiplex ${ }^{\mathrm{TM}}$ kit. Applied Biosystems) was realized with primers designed in the flanking regions to each of the SNP of interest. The genotypes were identified by minisequencing with ABIPrism 3130 and GeneMapper 3.7. (Applied Biosystems) and the different alleles of the seven SNPs were discriminated in a sole reaction. In this work have been detected, for the first time, the polymorphisms T221C and C233T of the LEPR gene (Genbank AF092422), which are not recognizable by restriction. This method allows identifying the carrying animals with the best desirable genotypes for selection.

Arch. Zootec. 59 (226): 233-244. 2010. 


\section{INTRODUCCIÓN}

En el sector porcino se esta comenzando a aplicar la selección asistida por marcadores para mejorar la calidad y rendimiento de los animales (Van der Steen et al., 2005). Los SNPs (single nucleotide polymorphisms) son los marcadores moleculares que se están utilizando en la evaluación de estos caracteres. Aunque se han detectado miles de lugares polimórficos SNPs en porcino (USMARC, NCBI SNP database), sólo unos pocos se han asociado con caracteres económicamente importantes. La identificación precoz de los animales portadores de los SNPs de interés puede incrementar la precisión de la selección y, por tanto, la eficacia de los Programas de Mejora, pero la evaluación sólo será eficiente con un método rápido y fiable de detección de SNPs. Existe una amplia gama de métodos y tecnologías para la detección de SNPs (AS-PCR, OLA ligación de oligonucleótidos, hibridación, etc.; Syvänen, 2001) que superan algunas dificultades del método clásico PCR-RFLP (Suda et al., 2003). La elección del método es crítica para responder a las necesidades prácticas.

El método primer extension o minisecuenciación (Syvänen, 1999) se basa en la detección de la extensión de un único dideoxinucleótido (ddNTPs) marcado fluorescentemente a partir de un cebador específico no marcado. El kit de reactivos comercial SNaPshot (Applied Biosystems) permite la detección multiple de varios SNPs, pero es necesario diseñar los cebadores de PCR para la generación de los amplicones que contengan los lugares polimórficos y los cebadores específicos de extensión que interrogan el lugar SNP.

Entre los genes con influencia sobre la cantidad y calidad de carne de porcino (Kollers et al., 2005) de los que se tenía evidencia de polimorfismos específicos, se han elegido para el análisis múltiple SNaPshot los genes H-FABP, MC4R y LEPR, por la función que realizan (formación del músculo, ingesta de alimentos, metabolismo y almacenamiento de grasa), por el conocimiento de su variabilidad, la longitud del fragmento de PCR específico y la posición de la mutación seleccionada, o porque no sean reconocibles por los métodos clásicos de restricción.

El gen H-FABP codifica una proteína relacionada con el transporte intracelular de ácidos grasos en el músculo esquelético y con la regulación del metabolismo lipídico. Este gen fue ubicado en una región del cromosoma 6 (Gerbens et al., 1997, 2000) que contenía un QTL para caracteres de grasa (Ovilo et al., 2002a; Yue et al., 2003). Se han evaluado los efectos de tres SNPs: Las sustituciones nucleotídicas del intrón2 C1489T y C1811G del gen H-FABP (GenBank Y16180) y la sustitución T1324C de la región reguladora 5'UTR del gen (GenBank X98558). Gerbens et al. (1999) en cerdos Duroc, encontraron una asociación significativa entre estos tres SNPs y el contenido en grasa intramuscular, grasa dorsal y peso corporal.

El receptor 4 de la melanocortina (MC4R) es una de las moléculas relacionadas con la regulación del comportamiento alimentario y el peso corporal. El gen que codifica esta proteína se considera, por tanto, candidato para caracteres de engrasamiento y crecimiento. En este gen, Kim et al. (2000) detectaron una sustitución nucleotídica G1426A no sinónima (Asp298Asn) en la secuencia del gen (GenBank AB021664), que ha mostrado una asociación significativa con el espesor del tocino dorsal, el crecimiento y el consumo de alimentos.

Los genes de la leptina (LEP) y su receptor (LEPR) influyen en la regulación del peso corporal regulando el control de la ingesta y la actividad metabólica celular. Se han identificado dos lugares polimórficos en la secuencia del exón 4 del gen LEPR (GenBank AF092422): la sustitución T221C (Ovilo et al., 2002b), no reconocible por ninguna de las enzimas de restricción disponibles, causa un cambio Met/Thr en la 


\section{DETECCIÓN MULTIPLE DE SNPs EN PORCINO}

secuencia del polipéptido codificado, y una sustitución dinucleotídica T232A y C233T, que puede crear cuatro codones: TCA (serina); ATA (isoleucina); TTA (leucina); $\underline{\mathrm{ACA}}$ (treonina). En la sustitución $\mathrm{TC} \rightarrow \mathrm{AT}$ solamente el primer nucleótido (T232A) es reconocible por restricción con Tsp509I (AATT) (Mackowski et al., 2005). Esta mutación parece estar asociada con la topografía de la grasa (Mackowski et al., 2005).

En este trabajo se aborda un método fiable, basado en la técnica de minisecuenciación, para el genotipado simultáneo de los 7 SNPs, como base para la evaluación rutinaria del rendimiento cárnico en el ganado porcino para sustituir a las técnicas de secuenciación y PCR-RFLP actualmente utilizadas.

\section{MATERIAL Y MÉTODOS}

La detección de los 7 polimorfismos de una sola base (SNPs) se realizó con la técnica de minisecuenciación o Primer extension (Syvänen, 1999). Se diseñaron los cebadores de PCR utilizados para la obtención de los amplicones que contienen los SNPs. El diseño de cebadores de PCR se realizó mediante el programa Primer3 v0.3.0 (http:// frodo.wi.mit.edu) de Rozen y Skaletsky (2000). Se utilizaron secuencias de 200 bases aguas arriba y aguas abajo a partir de la posición de cada SNP, excluyendo 30 bases a ambos lados del SNP. Se utilizaron los parámetros $\left(\mathrm{t}_{\mathrm{m}}\right.$, longitud, $\% \mathrm{GC}$, etc.) establecidos por defecto en el programa Primer3. Mediante el programa OligoAnalizer 3.0 de Integrated DNA Technologies (http:/ /www.idtdna.com/analyzer/Applications/ OligoAnalyzer, se obtuvieron los valores de estabilidad termodinámica (energía libre de Gibbs; $\Delta \mathrm{G}^{\circ}$ ) de las interacciones detectadas entre cebadores (formación de horquillas, homodímeros o heterodímeros) que pueden dar lugar a errores en las reacciones de PCR

Los cebadores de extensión fueron diseñados aguas arriba o aguas abajo y adya- centes al lugar polimórfico SNP, de forma que tuvieran una $\mathrm{t}_{\mathrm{m}}$ predicha de alrededor de $60^{\circ} \mathrm{C}$ y evitando que formaran estructuras secundarias estables entre ellos. Los cebadores de extensión se examinaron frente al resto de los amplicones molde para evitar una posible hibridación no específica. Las longitudes de los cebadores se modificaron por la adición de colas dinucleotídicas (dAT) al extremo 5'.

Las reacciones de PCR se realizaron en volúmenes de $25 \mu \mathrm{l}$, conteniendo $100 \mathrm{ng}$ de ADN genómico, 1,5 mM de $\mathrm{MgCl}_{2}, 0,2 \mathrm{mM}$ dNTPs, 0,4 mM de cada cebador, 1 x Buffer y $0,5 \mathrm{U}$ de Taq polimerasa (Biotools). Las amplificaciones se han llevado a cabo en un termociclador PTC 200 (MJ Research) con diferentes condiciones de amplificación según el fragmento, exceptuando las diferencias recogidas en la tabla I en relación con el número de ciclos y la temperatura de hibridación utilizada para cada loci. Los diferentes fragmentos se amplificaron en condiciones uniformes: $94^{\circ} \mathrm{C} / 4 \mathrm{~min} ; 30 \mathrm{ci}-$ $\operatorname{clos}\left(94^{\circ} \mathrm{C} / 30 \mathrm{seg}, 60^{\circ} \mathrm{C} / 30 \mathrm{seg}, 72^{\circ} \mathrm{C} / 30 \mathrm{seg}\right)$ y una extensión final de $72^{\circ} \mathrm{C} / 15 \mathrm{~min}$.

Los productos de reacciones separadas se mezclaron a volúmenes iguales y se purificaron a $37^{\circ} \mathrm{C}$ durante $90 \mathrm{~min}$ con $5 \mathrm{U}$ de Fosfatasa alcalina (SAP) y $2 \mathrm{U}$ de Exonucleasa I por cada $15 \mu$ lde reacción PCR, e incubando a $37^{\circ} \mathrm{C}$ durante $90 \mathrm{~min}$. La acción enzimática se desactivó a $80^{\circ} \mathrm{C}$ durante $20 \mathrm{~min}$.

El examen de los siete SNPs se realizó en una única reacción utilizando el kit $\mathrm{ABI}$ PRISM ${ }^{\circledR}$ SNaPshot Multiplex ${ }^{\mathrm{TM}}$ (Applied Biosystems; Forster City, CA, USA). Cada reacción de minisecuenciación $\mathrm{SNaPshot}$ $(10 \mu \mathrm{l})$ contenía $3 \mu \mathrm{l}$ de la mezcla de reacción del kit, $1 \mu \mathrm{l}$ de una mezcla de los cebadores internos o de extensión a concentraciones equimolares, $3 \mu \mathrm{l}$ de PCR molde $(0,2 \mathrm{pmol})$ y $3 \mu \mathrm{l}$ de agua desionizada. Las condiciones del termociclado para la reacción de extensión fueron 25 ciclos a $96^{\circ} \mathrm{C} / 10$ seg y $60^{\circ} \mathrm{C} /$ $35 \mathrm{seg}$. El exceso de ddNTPs marcados fluorescentemente fueron inactivados por la adición de $1 \mathrm{U}$ de fosfatasa alcalina (SAP) 
e incubación a $37^{\circ} \mathrm{C}$ durante $60 \mathrm{~min}$, y desactivándola después a $80^{\circ} \mathrm{C}$ durante 20 min.

Los productos resultantes se separaron mediante electroforesis capilar en un secuenciador automático ABIPrism 3130, mezclando $14 \mu \mathrm{ldeHi}$-Di formamide (Applied Biosystems), 0,4 $\mu$ lde LIZ-120 como estándar interno de tamaños (Applied Biosystems), y $0,9 \mu 1$ de la reacción de extensión tratada con SAP. La identificación de los genotipos se realizó mediante el software GeneMapper ver. 3.7 (Applied Biosystems; Forster City, CA, USA).

La fiabilidad del método de genotipado se contrastó por secuenciación doble de 2 animales de cada uno de los genotipos detectados, empleando secuenciación cíclica (BigDye Terminator v.3.1 Cycle sequencing Kits. Applied Biosystems; Forster City, CA, USA) de los productos de los 4 genes.

Para la verificación del método de identificación de los genotipos se analizaron un total de 193 animales de diversas razas porcinas y de su pariente salvaje el jabalí (tabla VI). El ADN genómico de cada animal fue extraído utilizando el procedimiento propuesto por el fabricante del kit Ultra Clean ${ }^{T M}$
DNA Blood Spin ${ }^{T M}$ (MoBio) a partir de sangre completa (Duroc, Ibéricos y LWLD x LW) o de lisados hepáticos en el caso de los jabalíes. Las muestras de sangre de los animales Ibéricos y Duroc, procedían de los rebaños experimentales del Centro de Selección y Reproducción Animal (CENSYRA) de Badajoz. Las muestras de sangre de cerdos comerciales se obtuvieron en los mataderos de Cáceres y Arroyo de la Luz (Cáceres). Las muestras hepáticas procedían de jabalíes abatidos en las monterías de las campañas de 2006/07 en Extremadura.

Para cada población analizada se han estimado las frecuencias alélicas mediante el programa GENEPOP 4.0 (Raymond y Rousset, 1995).

\section{RESULTADOSYDISCUSIÓN}

En la tabla I se presentan las secuencias de los cebadores de PCR seleccionados a partir de las secuencias de los genes HFABP(GenBank X98558), MC4R(GenBank AB021664) y LEPR (GenBank AF092422), sus tamaños, $t_{m}$ y el tamaño esperado del fragmento amplificado en cada reacción de PCR. Además se presenta el $n^{\circ}$ de ciclos y la

Tabla I. Cebadores de PCR utilizados para la obtención de los amplicones. (PCR primer pairs designed for obtention of amplicons).

\begin{tabular}{|c|c|c|c|c|c|c|}
\hline Locus & Secuencia $\quad 5^{\prime} \rightarrow 3^{\prime}$ & $\mathrm{pb}$ & $t_{m}$ & $\begin{array}{l}\mathrm{N}^{\circ} \mathrm{de} \\
\text { ciclos }\end{array}$ & $\begin{array}{l}\mathrm{Ta} \\
{ }^{\circ} \mathrm{C}\end{array}$ & $\begin{array}{c}\text { Tamaño } \\
\mathrm{pb}\end{array}$ \\
\hline \multirow{2}{*}{ H-FABP AD* } & F:ATTGCCTTCGGTGTGTTTGAG & 21 & 62,3 & 5 & 63 & \multirow{2}{*}{816} \\
\hline & R:TCAGGAATGGGAGTTATTGG & 20 & 57,5 & 25 & 60 & \\
\hline \multirow{2}{*}{$\mathrm{H}-\mathrm{FABPH}$} & F:CAGCCCAAGAGTGAGTTTCC & 20 & 59,8 & \multirow{2}{*}{30} & \multirow{2}{*}{63} & \multirow{2}{*}{185} \\
\hline & R:AGGACCAGTCCCCTTTCCT & 19 & 59,9 & & & \\
\hline \multirow[t]{2}{*}{ MC4R } & F:TTGATTGGGGTCTTTGTGGT & 20 & 60,2 & \multirow{2}{*}{30} & \multirow{2}{*}{60} & \multirow{2}{*}{194} \\
\hline & R:TTGAAGGTTTTCCTCAGTTCTTG & 23 & 59,9 & & & \\
\hline \multirow[t]{2}{*}{ LEPR } & F:CTCTTGCCTGCTGGAATCTC & 21 & 60,1 & \multirow[t]{2}{*}{30} & \multirow[t]{2}{*}{60} & \multirow[t]{2}{*}{183} \\
\hline & R:CCTTCCCTGCAATGTTGTCT & 20 & 60,1 & & & \\
\hline
\end{tabular}

${ }^{*}$ Cebadores diseñados por Gerbens et al., 1997. 


\section{DETECCIÓN MULTIPLE DE SNPs EN PORCINO}

Tabla II. Formación de dímeros y horquillas entre las parejas de cebadores de PCR. HMD= homodimero, $H T D=$ heterodímero. (Formation of dimers and hairpins between PCR primer pairs. $\mathrm{HMD}=$ self-dimer; $\mathrm{HTD}=$ hetero-dimer).

\begin{tabular}{|c|c|c|c|c|c|c|}
\hline Cebadores & $\begin{array}{c}\left(\Delta \mathrm{G}^{\circ}\right)^{*} \\
\mathrm{kcal} / \mathrm{mol} .\end{array}$ & $\begin{array}{l}N^{\circ} \text { de } \\
\text { HTD }\end{array}$ & $\begin{array}{c}\text { HTD } \\
\text { más estable* }\end{array}$ & $\begin{array}{l}N^{\circ} \text { de } \\
\text { HMD }\end{array}$ & $\begin{array}{c}\text { HMD } \\
\text { más estable* }\end{array}$ & Horquillas** \\
\hline H-FABPAD foward & $-40,33$ & \multirow{2}{*}{13} & \multirow{2}{*}{$-7,81$} & 6 & $-3,61$ & $1\left(0,54 / 16,7^{\circ} \mathrm{C}\right)$ \\
\hline H-FABPAD reverse & $-37,15$ & & & 7 & $-3,42$ & $1\left(-0,77 / 37,3^{\circ} \mathrm{C}\right)$ \\
\hline $\mathrm{H}-\mathrm{FABP} \mathrm{H}$ foward & $-37,84$ & \multirow{2}{*}{15} & \multirow{2}{*}{$-4,64$} & 7 & $-3,14$ & $1\left(0,09 / 23,3^{\circ} \mathrm{C}\right)$ \\
\hline $\mathrm{H}-\mathrm{FABP} \mathrm{H}$ reverse & $-38,06$ & & & 7 & $-6,24$ & $1\left(-1,59 / 42,7^{\circ} \mathrm{C}\right)$ \\
\hline MC4R foward & $-38,12$ & \multirow{2}{*}{13} & \multirow{2}{*}{$-3,54$} & 2 & $-1,57$ & $1\left(0,71 / 16^{\circ} \mathrm{C}\right)$ \\
\hline MC4R reverse & $-40,99$ & & & 11 & $-4,67$ & $1\left(-1,38 / 47,2^{\circ} \mathrm{C}\right)$ \\
\hline LEPR foward & $-37,93$ & \multirow{2}{*}{8} & \multirow{2}{*}{$-7,04$} & 7 & $-3,14$ & $1\left(-1,99 / 55,6^{\circ} \mathrm{C}\right)$ \\
\hline LEPR reverse & $-38,1$ & & & 5 & $-7,05$ & $1\left(-0,16 / 27,6^{\circ} \mathrm{C}\right)$ \\
\hline
\end{tabular}

*Estabilidad termodinámica definida por energía libre de Gibbs $\left(\Delta \mathrm{G}^{\circ}\right)$ en $\mathrm{kcal} / \mathrm{mol}$. Valores por defecto: concentración de $\mathrm{Na}+0,25 \mu \mathrm{M}$; concentración de oligonucleótidos $0,25 \mu \mathrm{M}$.

${ }^{*}$ Relación de valores: $n^{\circ}$ de estructuras terciarias $\left(\Delta G^{\circ}\right.$ de la más estable/temperatura de formación de dicha estructura). Valores por defecto: temperatura $25^{\circ} \mathrm{C}$; concentración de $\mathrm{Mg}^{2+} 0 \mathrm{mM}$; concentración de $\mathrm{Na}^{+} 0,25 \mu \mathrm{M}$; concentración de oligonucleótidos $0,25 \mu \mathrm{M}$; límite de plegamientos, 20 .

temperatura de hibridación utilizados en su amplificación. Para incrementar la especificidad de la PCR y el éxito de tipificación de muestras degradadas, los tamaños de los amplicones resultantes de las PCR diseñadas fueron menores de $200 \mathrm{pb}$.

En la tabla II se presentan los valores de estabilidad termodinámica $\left(\Delta \mathrm{G}^{\circ}\right)$ de las interacciones entre cebadores (formación de horquillas, homodímeros o heterodímeros). Se seleccionaron las parejas de cebadores con valores de estabilidad altos, es decir, con energía libre de Gibbs cercana a 0 (en un rango entre -7 y 0$)$. En las parejas de cebadores H-FABPAD (F y R) y LEPR (F y $\mathrm{R})$ pueden producirse heterodímeros más o menos estables. Ninguna de las horquillas que pueden formar los cebadores seleccio-

Tabla III. Cebadores de extensión para la amplificación múltiple de los 7 SNPS. (Extesion primers for the multiplex detection of 7 SNPs).

\begin{tabular}{|c|c|c|c|c|c|}
\hline Locus & SNP & Cebador Secuencia & $\mathrm{n}^{\circ} \mathrm{pb}$ & $t_{m}{ }^{\circ} \mathrm{C}$ & {$[\mu \mathrm{M}]$} \\
\hline H-FABP A & C1489T & GGGACATCTACCCTCTCTCAGGA 3' & 23 & 59,6 & 1,0 \\
\hline H-FABPD & C1811G & $(\mathrm{dAT})_{5}$-CGCCAACAGTTCTATGGGATG & 31 & 59,0 & 1,0 \\
\hline $\mathrm{H}-\mathrm{FABPH}$ & T1324C & $(\mathrm{dAT})_{8}$-CCAGCGGCTTCCTTCTCAGAT & 37 & 61,7 & 1,0 \\
\hline $\mathrm{MC}^{*} \mathrm{R}^{*}$ & G1426A & (dAT) ${ }_{11}$ A-CGGAGTGCATAAATCAGGGGAT & 45 & 61,0 & 0,5 \\
\hline LEPRH1 & T221C & $(\mathrm{dAT}){ }_{14} \mathrm{~A}-\mathrm{GACATGATGAGGCAGTTGTTGAAA}$ & 53 & 61,0 & 0,25 \\
\hline LEPRH2 & T232A & $(\mathrm{dAT})_{18}$-GGCAGTTGTTGAAACGGAACTTAAT & 61 & 60,0 & 1,0 \\
\hline LEPRH3* & C233T: & \multirow{2}{*}{$\begin{array}{l}\text { (dTA) }{ }_{16} \text { T-GTTTTAGAAGATAAGTTTGATAAGTA } \\
\text { GGTACCACTT }\end{array}$} & 60 & $00-5$ & \\
\hline & & & 69 & 60,5 & 0,5 \\
\hline
\end{tabular}

${ }^{*}$ Cebadores diseñados complementarios a la cadena directa. 
nados implica un riesgo a considerar en las reacciones de PCR.

En la figura 1 se muestran los amplicones PCR obtenidos una vez optimizadas la composición de la mezcla y las reacciones de amplificación. Para ello se modificaron, de grado en grado, las temperaturas de hibridación $(\mathrm{Ta})$, a partir de la $\mathrm{t}_{\mathrm{m}}$ media de cada pareja de cebadores (tabla I), hasta conseguir la amplificación específica del fragmento deseado. Así, en el caso del amplicón HFABP AD se aumentó la eficacia de la reacción forzando a los cebadores a hibridar primero a $63^{\circ} \mathrm{C}$ durante 5 ciclos y posteriormente a $60^{\circ} \mathrm{C}$ durante 25 ciclos. Las condiciones finales se indican en material y métodos.

En la tabla III se presentan los 7 cebadores de extensión diseñados, cada uno de tamaño diferente por la adición al extremo 5' de colas poli-AT de diferente

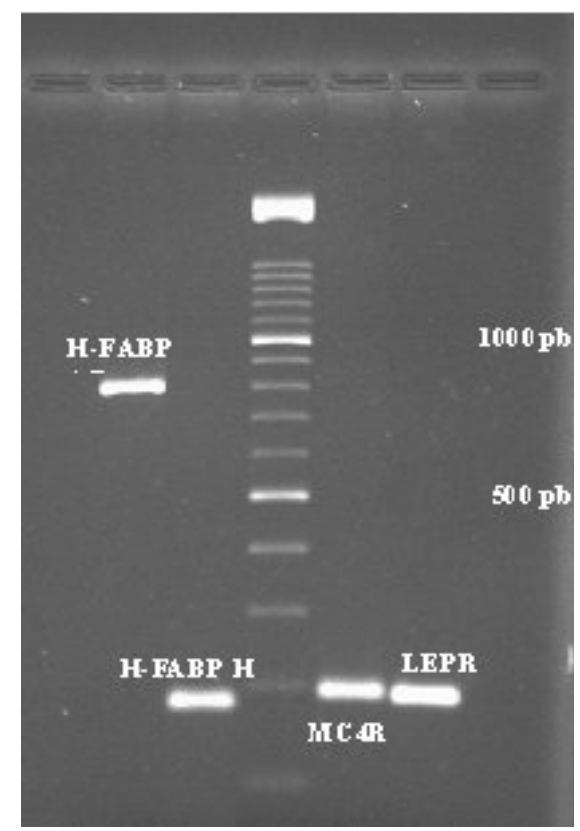

Figura 1. Fragmentos amplificados de cada uno de los genes. Gel de agarosa al $2 \% \mathrm{p} / \mathrm{v}$. (Amplified fragmnents of each genes analyzed. $2 \%(w / v)$ agarose gel). tamaño, a fin de facilitar su resolución electroforética.

Para identificar la sustitución dinucleotídica T232A y C233T del gen LEPR, reconocibles como $\mathrm{H} 2$ y $\mathrm{H} 3$ respectivamente, se diseñó el oligonucleótido de extensión LEPR H3 en la cadena complementaria para evitar competencias de hibridación en lugares adyacentes de la cadena. Así mismo, el cebador de extensión del gen MC4R se diseñó complementario a la cadena directa para adecuar la temperatura de fusión a lo establecido en el protocolo de minisecuenciación múltiple.

En la formación de dímeros y horquillas intramoleculares en los cebadores de extensión, se detectan algunas potenciales interacciones no deseables (tabla IV). Así, existe cierta estabilidad termodinámica en la posible formación de homodímeros en los cebadores LEPR H3 y MC4R, y de los heterodímeros: H-FABP A=MC4R; H-FABP $\mathrm{D}=\mathrm{LEPR} \mathrm{H} 1$; H-FABP D=LEPR H 2 y LEPR $\mathrm{H} 2=\mathrm{LEPRH} 3$.

Para optimizar la reacción de extensión múltiple de los 7 SNPs fue necesario evaluar los resultados del ensayo completo, comprobando los componentes de la reacción de extensión, separación electroforética y tipificación de la señal fluorescente.

En la tabla III se indican las concentraciones óptimas para los cebadores de extensión. La cantidad de producto PCR generado no está correlacionado necesariamente con la eficiencia o la intensidad de señal observada en la reacción de extensión (Vallone et al., 2004). Sin embargo, las diferencias entre las intensidades fluorescentes (medidas en RFUs, relative fluorescence units) dependen de las concentraciones de los cebadores de extensión, de las interacciones entre ellos y de la eficacia de emisión fluorescente de cada fluorocromo.

La optimización del equilibrio de las señales fue un proceso iterativo a partir de reacciones de extensión con cebadores a concentraciones equimolares $(0,1 \mu \mathrm{M})$. Posteriormente, se redujeron las concen-

Archivos de zootecnia vol. 59, núm. 226, p. 238. 
Tabla IV. Valores de estabilidad termodinámica de los cebadores de extensión (en negrita) $y$ de los dímeros formados entre ellos ( $\mathrm{kcal} / \mathrm{mol})$. Para cada valor se indica el número de los posibles dímeros formados y el valor termodinámico del más estable (entre paréntesis). Homodimeros: subrayados en la diagonal. (Thermodynamic stability values of extensión primers (in bold) and the dimers formed between them $(\mathrm{kcal} / \mathrm{mol})$. Each value shows the number of the total possible dimers formed and the thermodynamic value of the most stable (in brackets). Homodimers: underlining in diagonal).

\begin{tabular}{|c|c|c|c|c|c|c|c|}
\hline $\begin{array}{l}\text { Cebadores } \\
\text { de extension }\end{array}$ & $\begin{array}{c}\text { H-FABPA } \\
-41,82\end{array}$ & & & & & & \\
\hline H-FABPA & $18(-6,14)$ & $\begin{array}{c}\text { H-FABPD } \\
-40,6\end{array}$ & & & & & \\
\hline H-FABPD & $20(-6,14)$ & $13(-5,02)$ & $\begin{array}{c}\text { H-FABPH } \\
-42,66\end{array}$ & & & & \\
\hline H-FABPH & $20(-6,24)$ & $17(-6,75)$ & $14(-4,74)$ & $\begin{array}{l}\text { MC4R } \\
-43,33\end{array}$ & & & \\
\hline MC4R & $21(-7,24)$ & $18(-4,39)$ & $23(-4,67)$ & $11(-7,05)$ & $\begin{array}{c}\text { LEPRH1 } \\
-42,18\end{array}$ & & \\
\hline LEPRH1 & $21(-6,24)$ & $17(-7,19)$ & $23(-5,13)$ & $16(-5,09)$ & $15(-5,38)$ & $\begin{array}{c}\text { LEPRH2 } \\
-46,81\end{array}$ & \\
\hline LEPRH2 & $19(-3,53)$ & $15(-7,19)$ & $21(-6,59)$ & $17(-5,09)$ & $19(-4,88)$ & $17(-4,88)$ & $\begin{array}{c}\text { LEPRH3 } \\
-56,33\end{array}$ \\
\hline LEPRH3 & $27(-5,37)$ & $20(-6,08)$ & $20(-6,72)$ & $23(-4,85)$ & $25(-3,89)$ & $30(-7,79)$ & $\underline{31}(-9,78)$ \\
\hline
\end{tabular}

traciones de los cebadores de extensión de los loci que exhibían una fuerte intensidad de señal y se incrementaron para los loci con peores señales. La ausencia de señal del LEPR H2 (figura 2) en combinaciones equimolares con LEPR H3 y H-FABPD (ambos con fuertes intensidades de señal), concuerda con los resultados obtenidos por el programa OligoAnalizer 3.0, que predecía cierta estabilidad de los heterodímeros LEPR H2=LEPR H3 y LEPR H2=H-FABPD (tabla IV). Este proceso se repitió hasta que se alcanzó el equilibrio de señales. Las intensidades de señal varían dependiendo del ddNTP marcado que se incorpore en la extensión. La señal resultante de la incorporación de ddG fue más intensa que los ddT.

En la figura 3 se muestran los electroferogramas de dos muestras en las que se indican con las diferentes variantes alélicas de cada locus. Estos individuos fueron utilizados como muestras de referencia para la detección segura de los alelos esperados.

La migración electroforética de los

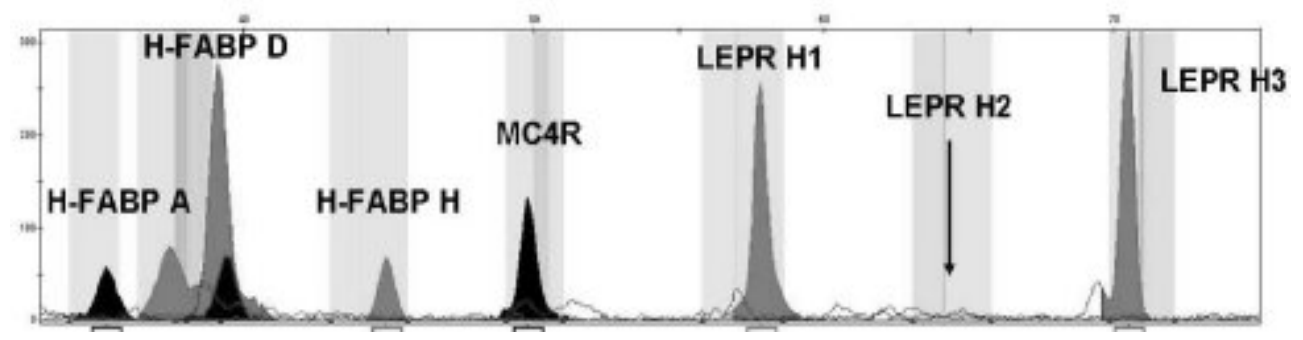

Figura 2. Reacción múltiple SNaPshot con los cebadores a concentraciones equimolares $(0,1 \mu \mathrm{M})$. (SnaPshot multiplex reaction representing equimolar $(0,1 \mu \mathrm{M})$ primer concentrations). 

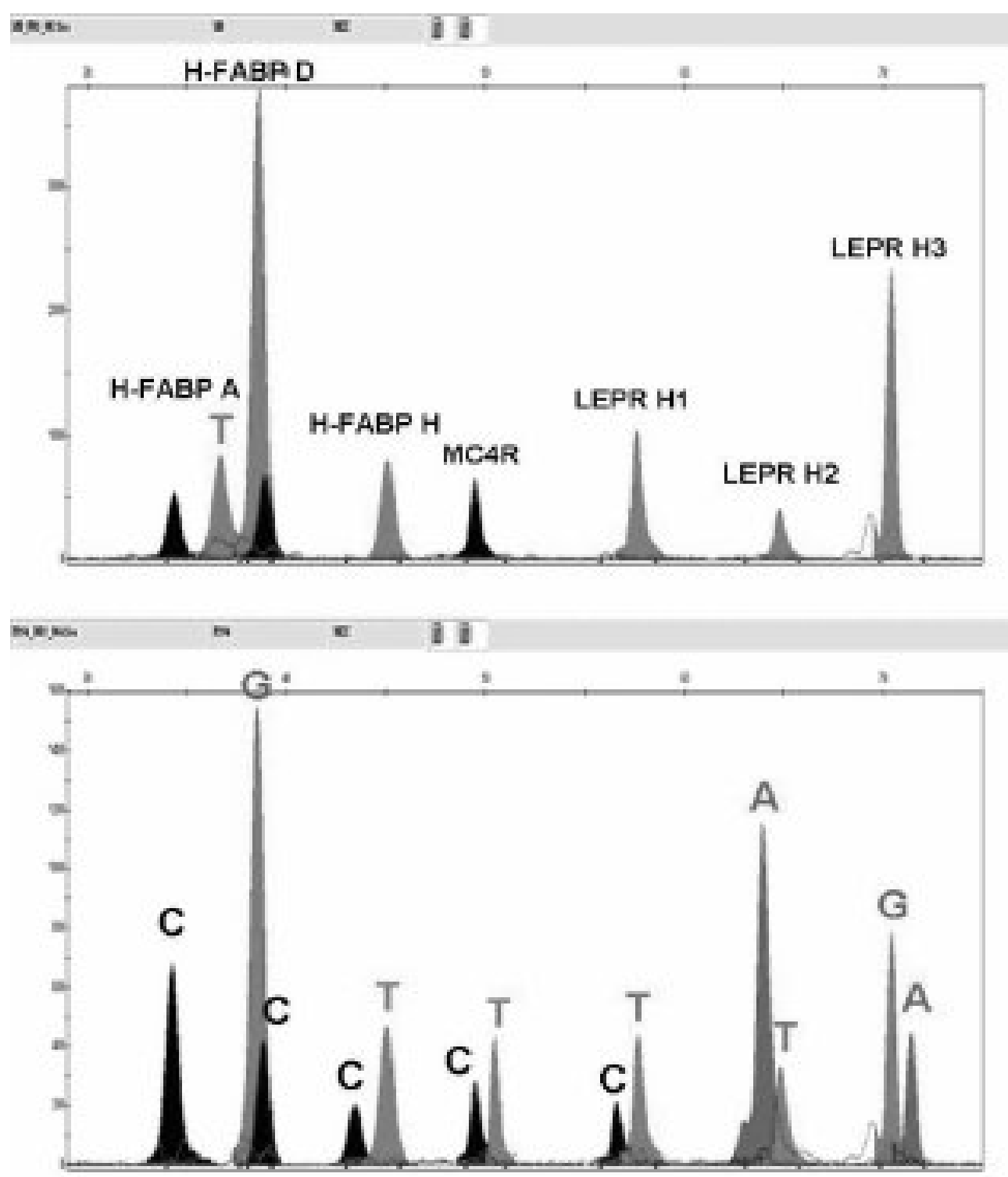

Figura 3. Electroferogramas de dos muestras que muestran las variantes alélicas de cada locus (arriba H-FABP A; abajo: resto de loci). (Electropherograms of two samples that exhibit the allele variation at each locus).

oligonucleótidos más cortos es más afectada por el fluorocromo marcador que la de los más largos. En la tabla $\mathbf{V}$ se presenta el $\Delta \mathrm{pb}$

(tamaño medio estimado-tamaño esperado) de cada alelo, la amplitud alélica y la distancia entre loci, el tamaño y distancia entre los 
DETECCIÓN MULTIPLE DE SNPs EN PORCINO

Tabla $\boldsymbol{V}$. Tamaño y distancia entre los productos de extension. (Sizing and spacing of primer extension products).

\begin{tabular}{lccccc}
\hline Locus & $\begin{array}{c}\text { Tamaño } \\
\text { esperado } \mathrm{pb}\end{array}$ & $\begin{array}{c}\Delta \mathrm{pb} \\
\text { alelo } 1\end{array}$ & $\begin{array}{c}\Delta \mathrm{pb} \\
\text { alelo } 2\end{array}$ & $\begin{array}{c}\text { Amplitud } \\
\text { alélica }{ }^{1}\end{array}$ & $\begin{array}{c}\text { Distancia } \\
\text { entre } \text { loci }^{2}\end{array}$ \\
\hline H-FABP A & 23 & 10,1 & 12,2 & $2,1 \mathrm{C} / \mathrm{T}$ & - \\
H-FABPD & 31 & 6,5 & 6,8 & $0,3 \mathrm{G} / \mathrm{C}$ & 4,7 \\
H-FABPH & 37 & 5,3 & 6,7 & $1,4 \mathrm{C} / \mathrm{T}$ & 6,2 \\
MC4R & 45 & 4 & 5,1 & $1,1 \mathrm{C} / \mathrm{T}$ & 7,8 \\
LEPRH1 & 53 & 3,3 & 4,6 & $1,0 \mathrm{C} / \mathrm{T}$ & 7,6 \\
LEPRH2 & 61 & 2,9 & 3,8 & $0,9 \mathrm{~A} / \mathrm{T}$ & 8,2 \\
LEPRH3* & 69 & 1,4 & 2,4 & $1,0 \mathrm{G} / \mathrm{A}$ & 8,5 \\
\hline
\end{tabular}

$\Delta \mathrm{pb}$ (tamaño estimado-tamaño esperado).

${ }^{1}$ Diferencia absoluta de tamaño entre los productos de extensión en un locus. ${ }^{2}$ Diferencia entre dos loci adyacentes $=$ diferencia entre el alelo más grande del locus $\mathrm{N}$ y el más pequeño del locus $\mathrm{N}-1$.

productos de extensión estimados como promedio en 30 individuos, con el polímero POP7. La precisión de las medidas de los tamaños para varios set de carreras fue menor de $0,1 \mathrm{pb}$. La variación de los tamaños para los cebadores extendidos depende de la longitud y composición de la secuencia y del tipo de marcador fluorescente unido (Vallone et al., 2004).

Los lugares polimórficos fueron ratificados por secuenciación doble de dos animales de cada uno de los genotipos detectados hallando plena coincidencia entre los genotipos definidos mediante primer extension y las secuencias encontradas en los animales secuenciados. Este método presenta, por tanto, una elevada precisión y fiabilidad. Con objeto de conocer su eficacia en el genotipado poblacional, el método se ha aplicado en la identificación de los genotipos de 193 animales de diferentes razas porcinas y de jabalíes. En la tabla VI se muestran los genotipos y las frecuencias alélicas encontradas en las diferentes razas y especies analizadas para cada uno de los SNPs estudiados.

El alelo G del locus MC4R que se ha asociado con menor espesor del tocino dorsal, menor tasa de crecimiento (medida como ganancia media diaria) y menor ingesta de alimentos, se encuentra fijado en la po- blación de jabalí y a frecuencias elevadas en la población de la raza Ibérica, que no ha sido seleccionada para estos caracteres con fines industriales. En las poblaciones de Duroc y cerdos blancos comerciales analizadas, los valores de las frecuencias de los alelos G/A son intermedias. Estos resultados son similares a los obtenidos por Burgos et al. (2006), que analizaron la incidencia alélica de este gen en las mismas razas.

No se tienen referencias bibliográficas sobre la incidencia alélica, o su asociación con caracteres productivos, de la mutación nucleotídica T/C del LEPR H1, ya que es la primera vez que ha sido estudiada en poblaciones animales. Esta mutación causa un cambio de Met a Thr (Mackowski et al., 2005) en el dominio extracelular de la secuencia del polipéptido codificado. En la tabla VI, el alelo T se encuentra fijado en las razas Ibérica y Duroc por lo que en esa posición siempre se traduce a Met. Por el contrario, en los jabalíes, el alelo C (Thr) se presenta en altas frecuencias, que son intermedias en los cerdos blancos analizados. La sustitución dinucleotídica TC / AT del gen LEPR ( $\mathrm{H} 2$ y H3) puede crear cuatro codones: TCA (serina); ATA (isoleucina); TTA (leucina); ACA (treonina) en la proteína codificada. En el jabalí y en las razas Ibérica y Duroc de porcino está fijado el haplotipo 
PADILLAETAL.

Tabla VI. Genotipos y frecuencias alélicas encontradas en las razas analizadas. $L W L D x L W$ : Large White-Landrace $x$ Large White. (Genotype and allele frequencies found in the analyzed breeds. LWLDxLW: Large White-Landrace $x$ Large White).

\begin{tabular}{|c|c|c|c|c|c|c|c|}
\hline \multirow[t]{2}{*}{ Locus } & \multirow[t]{2}{*}{ Raza } & \multirow[t]{2}{*}{$\mathrm{n}$} & \multicolumn{3}{|c|}{ Genotipos } & \multicolumn{2}{|c|}{ Frecuencias alélicas } \\
\hline & & & $\mathrm{CC}$ & CT & TT & C & $T$ \\
\hline \multirow[t]{4}{*}{ H-FABP A } & Jabalí & 27 & 17 & 6 & 4 & 0,741 & 0,259 \\
\hline & Ibérico & 54 & 34 & 18 & 2 & 0,796 & 0,204 \\
\hline & Duroc & 62 & 5 & 31 & 26 & 0,331 & 0,669 \\
\hline & LWLDxLW & 46 & 40 & 6 & 0 & 0,935 & 0,065 \\
\hline \multirow[t]{5}{*}{ H-FABP D } & & & $\mathrm{CC}$ & CG & GG & C & G \\
\hline & Jabalí & 29 & 0 & 2 & 27 & 0,035 & 0,965 \\
\hline & Ibérico & 54 & 34 & 18 & 2 & 0,796 & 0,204 \\
\hline & Duroc & 62 & 6 & 30 & 26 & 0,339 & 0,661 \\
\hline & LWLDxLW & 39 & 13 & 18 & 8 & 0,564 & 0,436 \\
\hline \multirow[t]{5}{*}{$\mathrm{H}-\mathrm{FABP} \mathrm{H}$} & & & $\pi$ & $\mathrm{TC}$ & $\mathrm{CC}$ & $\mathrm{T}$ & C \\
\hline & Jabalí & 29 & 29 & 0 & 0 & 1,000 & 0,000 \\
\hline & Ibérico & 54 & 54 & 0 & 0 & 1,000 & 0,000 \\
\hline & Duroc & 63 & 52 & 10 & 1 & 0,905 & 0,095 \\
\hline & LWLDxLW & 47 & 25 & 18 & 4 & 0,723 & 0,277 \\
\hline \multirow[t]{5}{*}{ MC4R } & & & GG & GA & AA & G & A \\
\hline & Jabalí & 29 & 29 & 0 & 0 & 1,000 & 0,000 \\
\hline & Ibérico & 54 & 36 & 16 & 2 & 0,815 & 0,185 \\
\hline & Duroc & 62 & 14 & 34 & 14 & 0,500 & 0,500 \\
\hline & LWLDxLW & 47 & 17 & 19 & 11 & 0,564 & 0,436 \\
\hline \multirow[t]{5}{*}{ LEPRH1 } & & & $T$ & $\mathrm{TC}$ & $\mathrm{CC}$ & $\mathrm{T}$ & C \\
\hline & Jabalí & 29 & 3 & 11 & 15 & 0,293 & 0,707 \\
\hline & Ibérico & 54 & 54 & 0 & 0 & 1,000 & 0,000 \\
\hline & Duroc & 62 & 62 & 0 & 0 & 1,000 & 0,000 \\
\hline & LWLDxLW & 47 & 14 & 26 & 7 & 0,575 & 0,425 \\
\hline \multirow[t]{5}{*}{ LEPRH2 } & & & $T T$ & TA & AA & $\mathrm{T}$ & A \\
\hline & Jabalí & 29 & 29 & 0 & 0 & 1,000 & 0,000 \\
\hline & Ibérico & 54 & 54 & 0 & 0 & 1,000 & 0,000 \\
\hline & Duroc & 62 & 62 & 0 & 0 & 1,000 & 0,000 \\
\hline & LWLDxLW & 47 & 40 & 7 & 0 & 0,925 & 0,075 \\
\hline \multirow[t]{5}{*}{ LEPRH3 } & & & CC & CT & $\pi$ & C & $\mathrm{T}$ \\
\hline & Jabalí & 29 & 29 & 0 & 0 & 1,000 & 0,000 \\
\hline & Ibérico & 54 & 54 & 0 & 0 & 1,000 & 1,000 \\
\hline & Duroc & 62 & 62 & 0 & 0 & 1,000 & 0,000 \\
\hline & LWLDxLW & 47 & 40 & 7 & 0 & 0,925 & 0,075 \\
\hline
\end{tabular}

TC correspondiente a serina. Solo unos pocos individuos de porcino blanco comercial presentaban el genotipo TACT, por lo que se desconoce cuál de los 4 aminoácidos posibles se incorporaría en la cadena polipeptídica. Mackowski et al. (2005), mediante secuenciación de estas posiciones SNPs sólo encontró dos haplotipos (TC y
AT), detectando mayor espesor de tocino dorsal en los heterocigotos (TA) que en los homocigotos TT del gen LEPR H2. Estos resultados son coherentes con que se haya encontrado el genotipo TA exclusivamente en cerdos blancos.

Los tres SNPs estudiados en el gen HFABP se presentan con diferentes frecuen- 


\section{DETECCIÓN MULTIPLE DE SNPs EN PORCINO}

cias según la raza estudiada. El locus $\mathrm{H}-$ FABP A $(\mathrm{C} / \mathrm{T})$ es polimórfico en todas las razas excepto en el cruzamiento comercial LWLDxLW que casi exclusivamente posee el alelo C, no habiéndose encontrado el genotipo TT. Este resultado es similar a lo encontrado por Nechtelberger et al. (2001) en las razas de porcino austriacas, Landrace, Piétrain y Large White y por Alfonso y Arana (2004) en una línea seleccionada comercial originaria de esta última raza. Similarmente, el alelo C es también el más frecuente en jabalí y en Ibérico, mientras que en Duroc el más frecuente fue el alelo T $(0,669)$. Alfonso y Arana (2004) en cerdos pío negro del País Vasco, de alto desarrollo adiposo, encontraron el alelo $\mathrm{T}$ a frecuencias similares $(0,72)$. La presencia de este alelo $\mathrm{T}$ se ha asociado con mayor contenido en grasa intramuscular, mayor espesor del tocino dorsal y mayor peso corporal en cerdos de la razas Duroc (Gerbens et al., 1999), y de otras razas chinas y europeas (Wei-Jun y Gong-She, 2006). Sin embargo, en Landrace ha sido el alelo C (Nechtelberger et al., 2001) el que se ha relacionado con mayor ganancia media diaria e índice de conversión de alimentos. En el locus HFABP D $(\mathrm{C} / \mathrm{G})$, el alelo $\mathrm{G}$ se presenta a frecuencias muy altas, casi fijado, en jabalí, siendo variable en el resto de razas analizadas. Este alelo se ha asociado con un mayor contenido en grasa intramuscular, mayor espesor del tocino dorsal y mayor peso corporal en cerdos de la raza Duroc (Gerbens et al., 1999). En Large White este alelo se ha asociado claramente con mayor ganancia media diaria (Nechtelberger et al., 2001). En

\section{BIBLIOGRAFÍA}

Alfonso, L. and Arana, A. 2004. Characterisation of some fatness candidate genes in Basque Black Pied and Large White pigs. Arch. Zootec., 53: 411-414.

Burgos, C., Carrodeguas, J.A., Moreno, C., Altarriba, J., Tarrafeta, L., Barcelona, J.A. and López-Buesa, P. 2006. Allelic incidence in several pig breeds of a missense variant of pig el caso del locus H-FABP H (T/C), el alelo T está fijado en jabalí y en porcino Ibérico, y se encuentra a frecuencia muy alta $(0,9)$ en Duroc, las dos razas porcinas con mayor contenido en grasa intramuscular. En este caso el alelo $\mathrm{T}$ se ha asociado claramente con un mayor contenido en grasa intramuscular y mayor espesor del tocino dorsal en cerdos de la raza Duroc (Gerbens et al., 1999). En Large White este alelo se ha asociado con mayor ganancia media diaria y color de la carne (Nechtelberger et al., 2001).

\section{CONCLUSIONES}

Este estudio muestra que el método $\mathrm{SNaPshot} \mathrm{puede} \mathrm{reemplazar} \mathrm{fiablemente} \mathrm{los}$ métodos de secuenciación y PCR-RFLP, particularmente en la detección de las mutaciones del exón 4 del gen LEPR H1 (T221C) y H3 (C233T) que no son reconocibles por ninguna endonucleasa de restricción. Una vez optimizado, el método de primer extension ha resultado ser rápido y fiable en la determinación del genotipo. En una sola reacción se discriminan 7 SNPs relacionados con la cantidad y calidad de la carne en porcino y puede servir para identificar y seleccionar los animales portadores de los genotipos más deseables.

\section{AGRADECIMIENTOS}

A los Drs. Calero y Antúnez del (CENSYRA) de Badajoz por facilitarnos muestras de porcino.

Este trabajo es parte del Proyecto PDT05B017. Junta de Extremadura. FEDER.

melanocortin-4 receptor (MC4R) gene associated with carcass and productive traits; its relation to IGF2 genotype. Meat Sci., 73: 144-150. Gerbens, F., Rettenberger, G., Lenstra, J.A., Veerkamp, J.H. and Te Pas, M.F.W. 1997. Characterization, chromosomal localization, and genetic variation of the porcine heart fatty acid-binding proteine gene. Mamm. 
Genome, 8: 328-332.

Gerbens, F., Van Erp, A.J.M., Harders, F.L. Verburg, F.J., Meuwissen, T.H.E., Veerkamp, J.H. and Te Pas, M.F.W. 1999. Effect on genetics variants of the Heart fatty acid-binding protein gene on intramuscular fat and performance traits in pig. J. Anim. Sci., 77: 846-852.

Gerbens, F., De Koning, D.J., Harders, F.L., Meuwissen, T.H.E., Janss, L.L.G., Groenen, M.A.M., Veerkamp, J.H., Van Arendonk, J.A.M and Te Pas, M.F.W. 2000. The effect of adipocyte and heart fatty acid binding protein genes on intramuscular fat and backfat content in Meishan crossbred pigs. J. Anim. Sci., 78: 552-559.

Kim, K.S., Larsen, N., Short, T., Plastow, G. and Rothschild, M.F. 2000. A missense variant of the procine melanocortin-4 receptor (MC4R) gene is associated with fatness, growth, and feed intake traits. Mamm. Genome, 11: 131-135.

Kollers, S., Mégy, K. and Rocha, D. 2005. Analysis of public single nucleotide polymorphisms in commercial pig populations. Anim. Genet., 36: 426-431.

Mackowski, M., Szymoniak, K., Szydlowski, M., Kamyczek, M., Eckert, R., Rozycki, M. and Switonski, M. 2005. Missense mutations in exon 4 of the porcine LEPR gene encoding extracellular domain and their association with fatness traits. Anim. Genet., 36: 135-137.

Nechtelberger, D., Pires, V., Solkner, J., Stur, I., Brem, G., Mueller, M. and Mueler, S. 2001. Intramuscular fat content and genetic variants at fatty acid-binding loci in Austrian pigs. J. Anim. Sci., 79: 2798-2804.

Ovilo, C., Oliver, A., Noguera, J.L., Clop, A., Barragán, C., Varona, L., Rodríguez, C., Toro, M., Sánchez, A., Pérez-Enciso, M. and Silió, L. 2002a. Test for positional candidate genes for body composition on pig chromosome 6 . Genet. Sel. Evol., 34: 465-479.

Ovilo, C., Melendez, B. and Benitez, J. 2002b. Study of polymorphism of leptin receptor gene in Iberian and Landrace pigs. In: XXVIII International Conference on Animal Genetics, 11-15 August 2002. Goettingen, paper D097
(Ed. by B. Beening y J-N Meyer). Georg-AugustUniversity of Goettingen. Germany. pp. 123.

Raymond, M. and Rousset, F. 1995. GENEPOP (version 1.2): population genetics software for exact tests and ecumenicism. J. Heredity, 86: 248-249.

Rozen, S. and Skaletsky, H.J. 2000. Primer3 on the WWW for general users and for biologist programmers. In: Krawetz, S., Misener, S. (eds.). Bioinformatics Methods and Protocols: Methods in Molecular Biology. Humana Press. Totowa, NJ. pp. 365-386.

Suda, T., Katoh, M., Hiratsuka, M., Fujiwara, M., Irizawa, Y. and Oshimura, M. 2003. Use of real time RT-PCR for the detection of allelic expresión o fan imprinted gene. Int. J. Mol. Med., 12: 243-246.

Syvänen, A.C. 1999. From gels to chips: "minisequencing" primer extension analysis of point mutations and single nucleotide polymorphisms. Hum. Mutat., 13: 1-10.

Syvänen, A.C. 2001. Accesing genetic variation: genotyping single nucleotide polymorphisms. Nat. Rev. Genet., 2: 930-942.

Vallone, P.M., Just, R.S., Coble, M.D., Butler, J.M. and Parsons, T.J. 2004. A multiplex allelespecific primer extension assay for forensically informative SNPs distributed throughout the mitochondrial genome. Int. J. Legal. Med., 118: 147-157.

Van der Steen, H.A.M., Prall, G.F.W. and Plastow, G.S. 2005. Application of genomics to the pork industry. J. Anim. Sci., 83: E1-E8.

Wei-Jun, P. and Gong-She, Y. 2006. Relationship between genetic variations of 5 '-upstream and the second intron region of $H-F A B P$ gene and IMF content in eight pig breeds and wild pig. Chinese J. Agricul. Biotech., 3: 101-107.

Yue, G., Stratil, A., Kopecny, M., Schroffelova, D., Schroffel Jr., J., Hojny, J., Cepica, S., Davoli, R., Zambonelli, P., Brunsch, C., Sternstein, I., Moser, G., Bartenschlager, H., Reiner, G. and Geldermann, H. 2003. Linkage and QTL mapping for Sus scrofa chromosome 6. J. Anim. Breed Genet., 120: 45-55.

Archivos de zootecnia vol. 59, núm. 226, p. 244. 